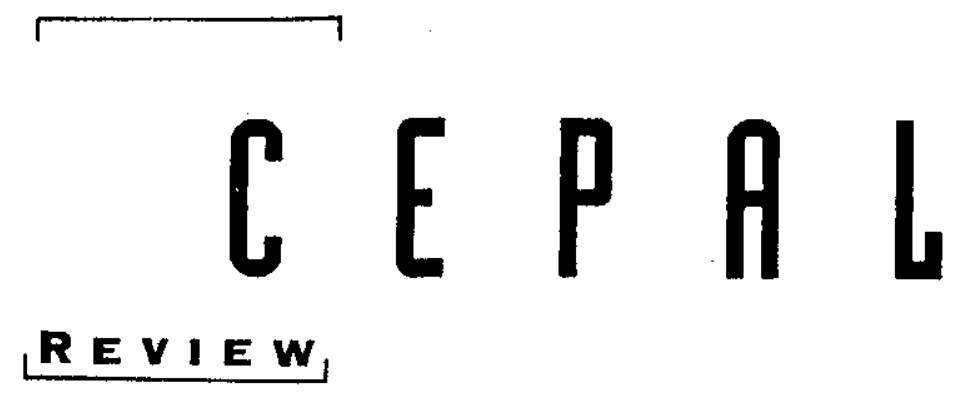

\author{
NUMBER 65 \\ AUGUST 1998 \\ SANTIAGO, CHILE \\ O S CAR ALTIMIA \\ Director of the Review \\ EUGENIO LAHERA \\ Technical Secretary
}

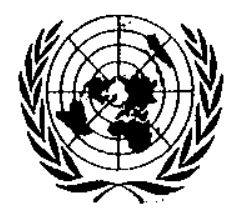


Income distribution, poverty and social expenditure in LatIn America

José Antonio Ocampo

Military expenditure and development in Latin America

Eugenio Lahera and Marcelo Ortúzar

Growth, dlstributive Justice and social policy

Andrés Solimano

Equity, foreign investment and international competitiveness

Adolfo Figueroa

Tensions in Latin American structural adjustment:

allocation versus distribution

Daniel M. Schydlowsky

Competitiveness and labour regulations

71

Luis Beccaria and Pedro Galín

Latin American families: convergences and divergences in models and pollcies

Irma Arriagada

Free trade agreements and female labour: the Chilean situation Alicia Frohmann and Pilar Romaguera

Macroeconomic trends in Paraguay from 1989 to 1997: consumption bubble and financial crisis Stephane Straub

The strategies pursued by Mexican firms in their efforts to become global players

Alejandra Salas-Porras

Regulating the private provision of drinking water and sanitation services

Terence $R$. Lee and Andrei S. Jouravlev

Quallty management promotion to improve competitiveness

Hessel Schuurman

Recent ECLAC publications 


\section{Income distribution, poverty and social expenditure in Latin America}

\section{José Antonio Ocampo}

Executive Secretary, ECLAC.
Great social inequality has long been a frustrating feature of Latin American economic development. Not in vain has Latin America been described as the region of the world with the highest levels of inequality of income distribution. Although the prevailing levels of poverty are lower than those typical of other parts of the developing world, they are still extremely high and, taking the region as a whole, are higher now than they were before the debt crisis. These are the conditions now confronting the new elements which have changed the economic and social dynamics of the region. Special mention may be made of four of these elements: the structural reforms embarked upon in all the countries, the accompanying process of globalization, the resumption of economic growth, and the new reforms initiated in the area of social expenditure and social services as part of the "second generation" reforms. This article puts forward some hypotheses about the effects of these new events on poverty and inequality and analyzes their implications for social policy. 


\section{I}

\section{Poverty, inequality and their determinants}

The "lost decade" was a period of marked deterioration in terms of poverty in Latin America. The region suffered a setback in this respect, and in 1990 its levels of poverty were even higher than those existing in the early 1970s. In the 1990s, in contrast, the recovery of economic growth has given rise to a substantial improvement in these indicators, although the regional average is still above the levels prevailing before the crisis. Thus, whereas in $198035 \%$ of households were in a state of poverty, that proportion stood at $41 \%$ in 1990 , and in 1994 the figure was still as high as $39 \%$ (figure 1). The 1980 s was also a period of deterioration in terms of income distribution. The expectations that the renewal of economic growth would reverse the latter trend have not come true, so that the levels of inequality today are still above the already high levels which existed before the debt crisis (IDB, 1997; ECLAC, 1997).

These global tendencies conceal heterogeneous patterns in the different countries of the region, of course. According to the existing comparative studies, there is only one such country -Uruguay- where the levels of both poverty and equity have improved compared with those observed at the beginning of the 1980s. In several other countries -Brazil, Panama and, according to some studies, Colombia- the levels

FIGURE 1

Latin America: Percentage of households in a state of poverty

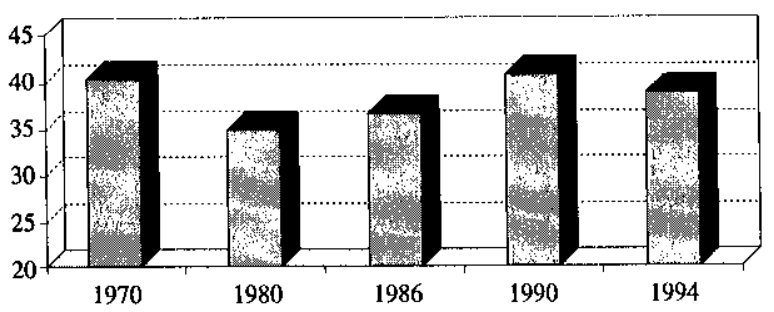

$\square$ This paper was presented at the First Conference of the Americas, held by the Organization of American States in Washington on 6 March 1998. of poverty have gone down, but the indicators of equity have not improved. The Chilean case is more complex: poverty has gone down markedly compared with the levels of the mid-1980s and even, perhaps, compared with those of the beginning of that decade (for which no estimates exist), but it has nevertheless barely recovered the levels of the early $1970 s,{ }^{1}$ while inequality of income distribution is greater than it was then and has been reluctant to go down even during the recent period of sharp reduction in poverty.

The attempts to explain these tendencies have given rise to a major controversy on the effects of macroeconomic behaviour, of structural reforms and of globalization on the social indicators. Since the pioneering essay by Morley (1994), several studies have confirmed that poverty tends to go down with economic growth, which would therefore explain the favourable behaviour displayed by this variable in response to the higher growth rates that have accompanied the reform process. In contrast, however, there is a growing group of studies which indicate that economic liberalization and globalization have tended to cause a deterioration in income distribution.

One of the authors who has been asserting this most forcibly in recent years is Albert Berry. This author has shown in various studies that there is evidence over the last quarter of a century that the application of economic liberalization measures has been associated with deterioration (sometimes serious) in income distribution (see, for example, Berry, 1997). According to Berry, this information is taken from the experiences of Argentina, Chile, Colombia, the Dominican Republic, Mexico and Uruguay, whereas Costa Rica is an exception to this rule. The comparative study by Robbins (1996) also shows that trade

\footnotetext{
1 Although there are problems of comparability of the figures, ECLAC (1990) estimated that the proportion of poor households in Chile was $38.1 \%$ in 1987, compared with $17 \%$ in 1970 , and the percentage of poor persons was $44.4 \%$ compared with $20 \%$ in those same years. Subsequent revisions slightly raised the 1987 estimates to $39.1 \%$ and $45.1 \%$ respectively. The most recent calculations, corresponding to 1996 , indicate that the percentages of poor households and poor persons have gone down to $19.7 \%$ and $23.3 \%$, respectively.
} 
openness processes have had unfavourable effects on equity in a number of countries of the region.

Recent ECLAC studies (see, for example, ECLAC, 1997 ) indicate that the main adverse pressures on income distribution in the present decade come from the increase in the disparity between the wages of the more highly skilled workers and those of the less skilled operatives, against a background of scant generation of skilled jobs and greater intrasectoral and intersectoral inequality in the product per person employed. Thus, there was an almost generalized increase in the wage gap in the countries of the region in the first half of the 1990 s (figure 2). The studies in question, like those of the ILO (see ILO, 1997), indicate that in the region employment has grown less than the economically active population and, in particular, the new jobs have been concentrated in the informal sector. According to the ILO's estimates, eight out of every ten jobs created in the 1990 s correspond to low-quality jobs in the informal sector.

The growing inequality in wages according to levels of skills of the labour force has not only been a feature of production restructuring processes in the region, for a recent report (UNCTAD, 1997) indicates that it may be an almost universal phenomenon, since it has affected a number of industrialized countries and some rapidly growing economies in the Asia-Pacific region and has given rise to particularly severe pressure on the middle classes of many countries.

There are various possible explanations for these trends. The most interesting is that of Rodrik (1997), according to which globalization heightens the asymmetrical relations between the factors that can cross national frontiers most easily -capital and highly skilled labour-- and those that cannot do this -less skilled labour. The possibility of relocating production activities means that the demand for labour is more elastic in all countries, thus reducing workers' bargaining capacity and increasing the instability of their income when there are upsets in demand.

Other authors have suggested different explanations. According to Berry (1997), there are important economies of scale in international trade and finance which are reflected in the greater participation in those activities of the biggest firms in each sector, which are also those that make the most intensive use of capital and/or more highly skilled labour. This would explain why a relative increase in the activities most closely associated with international trade could
FIGURE 2

Latin America: Differences in labour remuneration, 1990 and 1994

A. Between professionals and formal-sector workers

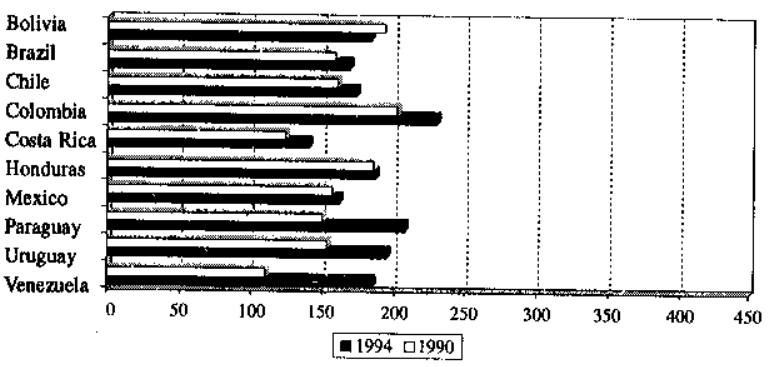

B. Between professionals and informal-sector workers

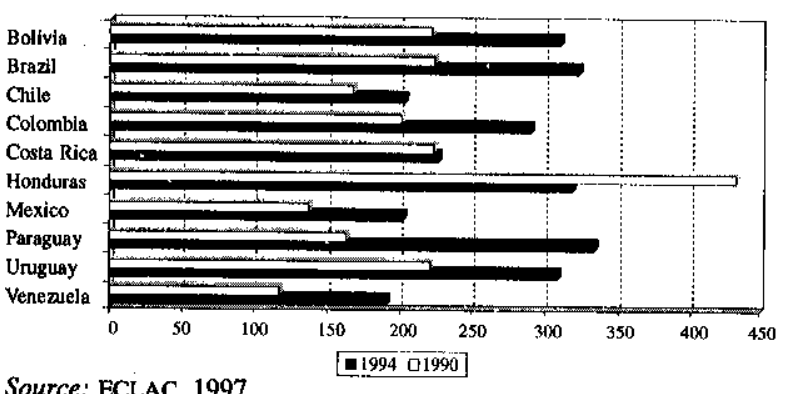

Source: ECLAC, 1997.

be reflected in greater inequality. It has also been suggested that the greater transfers of technology generated by trade itself, including technology transmitted through imports of machinery and equipment, can cause developing countries which are in the midst of internationalization processes to adopt skilledlabour-intensive technologies designed to serve the needs of the industrialized countries (Robbins, 1996).

In the case of Latin America, there may be further explanations complementary to this phenomenon. One of them is that the trade liberalization process took place after a decade of declining social expenditure. The bias in labour demand towards more highly skilled labour therefore came up against an inelastic supply of such workers. Moreover, during the liberalization process itself there were no clear efforts to link up the demand and supply of skills. Another possible explanation is that some elements of macroeconomic policy accompanying the reform process, especially the tendency towards currency revaluation and the opening up of the capital account, generated growth patterns in which exports displayed less dynamism that imports and the tradeable goods sectors showed less dynamism than the 
sectors producing non-tradeable goods and services, thus giving rise to skews in the demand for labour which were reflected in the relative behaviour of wages. ${ }^{2}$ Macroeconomic management has also been marked by severe "stop and go" cycles which, together with fluctuations in capital flows, have kept growth rates highly volatile, thus making it more difficult to generate more stable jobs.

The foregoing considerations are in no way intended to show that the economic reforms are responsible for the present levels of social inequality in the region: far from it. As we noted at the beginning of this article, inequality in Latin America has very deep roots. It is associated in particular with the great inequality in the distribution of human capital and wealth. ${ }^{3}$ Furthermore, in many countries the import substitution stage was marked by a deterioration in income distribution, and the experience of the $1980 \mathrm{~s}$ may be considered as convincing proof of the social costs associated both with macroeconomic imbalances (for example, the regressive effects of the destabilization of general price levels) and with the initial impact of the adjustment processes designed to correct this. At the same time, however, it would appear that although economic liberalization and globalization have had positive effects on growth they have increased the challenge to secure greater equity rather than reducing it.

\section{II}

\section{Public social expenditure and equity}

As may be gathered from the previous section, one of the great challenges in Latin America is to show that the new development model is compatible with the gradual correction of the great existing social inequalities. If this objective is not achieved, there could be a deterioration of the political bases of the reforms, which have been solid so far largely because the return to macroeconomic stability has been perceived by the population at large as a positive development. An equally serious danger is that social tensions might arise which could affect governance and erode the bases for the political consensuses which have made it possible to strengthen democracy in the region: undoubtedly one of the great achievements of recent years.

International experience bears witness to surprising results as regards the handling of the social risks involved in globalization. The study by Rodrik (1997) referred to earlier shows that in the past greater openness of the economy has been compensated by greater social protection of the population

\footnotetext{
${ }^{2}$ As a result of the trade openness process in itself and/or the incentives generated by macroeconomic policies, the linkages between the export sectors and the domestic economies have also been weakened, and the effect of this on the generation of employment should also be explored. It should be emphasized however, that as a result of the great increase in intraregional trade, part of these lower national linkages have been compensated by increased regional linkages.
}

on the part of the State, which has been reflected in a positive relation between the degree or openness and the size of the State sector. According to this author, this appraisal holds good both for the members of the Organization for Economic Cooperation and Development (OECD) and for a broad sample of 115 countries. This would appear to show that the distributive tension generated by economic openness processes has been dealt with so far by offsetting economic liberalization with greater State protection through more active social policy.

Social expenditure is undoubtedly the most important component through which the State can affect income distribution. There is a great deal of evidence that social expenditure has a significant effect on secondary income distribution. Moreover, in the long term greater investment in human capital makes it possible to affect one of the structural determinants of income distribution. The existing studies show that greater allocation of resources to education, which makes it possible to improve the distribution of human capital in a society, can have effects on income distribution which are much greater than those estimated in short-term income distribution incidence studies (see, for example, IDB, 1997, pp. 82-83). On a cautionary note, it should be emphasized that there is

\footnotetext{
${ }^{3}$ See, in this respect, the interesting study by Birdsall and Londoño, 1997.
} 
FIGURE 3

Latin America (10 countries): Targeting of social expenditure on the poor ${ }^{a}$

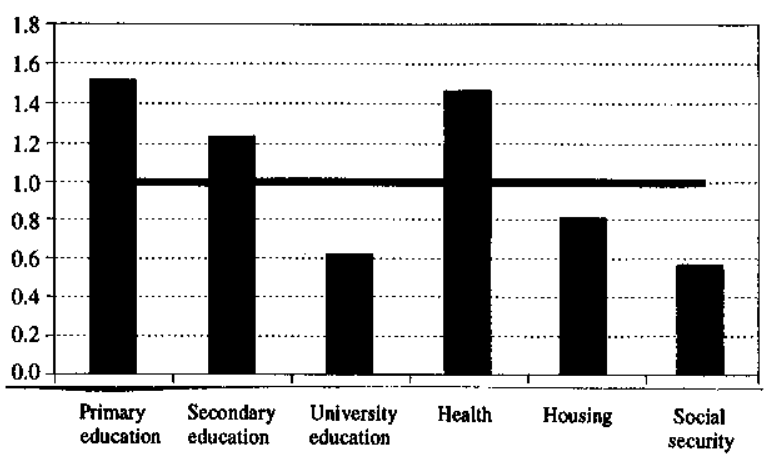

Source: ECLAC, 1998.

a The data presented refer to the average index of targeting of ten countries for which information is available. In the case of some sectors of expenditure, the information does not cover all these countries.

also evidence that a big effort in the field of education will tend to be reflected in decreasing returns on the investment in education, so that its redistributive consequences (although not its consequences for growth) may be somewhat overestimated. Important effects could also possibly be achieved if efforts were directed towards improving asset distribution (an area which has been very little explored and warrants greater attention), including the redistribution of assets without giving rise to distortions in economic activity (as in the case of institutional improvements to channel credit to small-scale or micro-enterprises without altering the credit market, or the new agrarian reform schemes which make active use of the land market).

The available data for Latin America on secondary income distribution indicate that in absolute terms the higher-income sectors derive more benefit from social expenditure. As a proportion of the income of each stratum, however, the subsidies channeled through such expenditure are greater for the poorest sectors of the population. This global pattern is the result of the very different distributive impacts of the different types of expenditure. The degree of targeting on the poor (i.e., the proportion of expenditure directed towards the poor compared with the proportion of the population which is in a state of poverty) is high in the case of expenditure on health, primary education and, to a lesser extent, secondary education (figure 3). In contrast, expenditure on social security and higher education displays a
FIGURE 4

Latin America: Soclal expenditure, 1981-1995

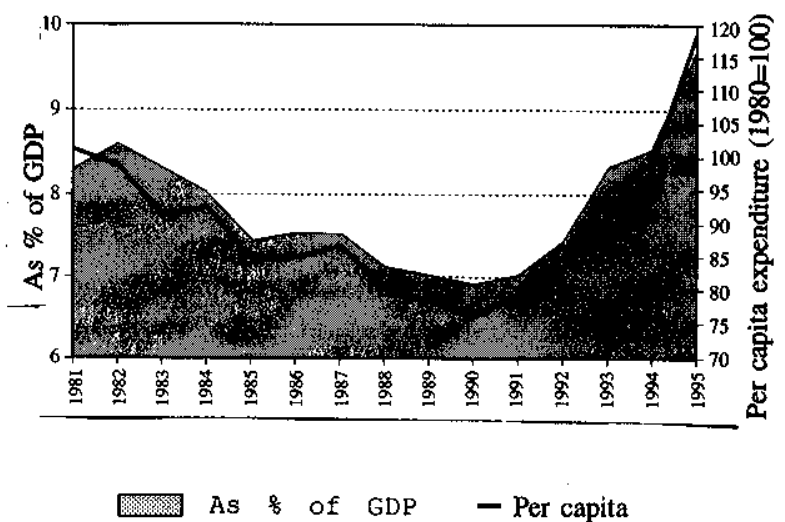

Source: ECLAC, 1998.

generally regressive tendency. Expenditure on housing is in an intermediate position, since it benefits in particular the middle strata of the income distribution table.

These results indicate that there is a good deal of room for improving income distribution through social expenditure, but there is also considerable room for improving the targeting of the latter, as noted in a recent ECLAC study. The way such expenditure is financed is of course highly relevant in this connection: financing from direct taxes tends to be more progressive than financing from indirect taxes and -equally important- an unsuitable form of financing which translates into higher inflation can wipe out the favourable effects in terms of redistribution (ECLAC, 1998, chap. VI).

The evolution of social expenditure in Latin America, according to that same study (see also ECLAC, 1997), is summarized in figure 4. The 1980s was marked by a collapse in social investment. Because of the dual effect of the smaller proportion of GDP devoted to social expenditure and the reduction in per capita income, real per capita social expenditure went down by $24 \%$. In the 1990 s, both these factors evolved positively, so that in 1995 per capita social expenditure was already $18 \%$ higher than the real levels registered before the crisis. This positive state of affairs must be qualified, however, in two different respects. Firstly, there continue to be big disparities between the countries of the region as regards the degree of priority given to social expenditure, so that 
in many of them social expenditure is still unsatisfactory in quantitative terms. Secondly, a very high proportion of the increase in social expenditure -especially in the countries where such expenditure is highest- has been directed to social security (and, more specifically, to pension payments), which is the component displaying the least progressive form of distribution. This means that the increase in expenditure on human capital has actually been smaller than the figures in question would appear to indicate. In the case of education, real per capita expenditure in 1995 had only recovered its 1980 level for the region as a whole and was still below that level in a considerable number of individual countries.
As may be gathered from the foregoing considerations, there is a good deal of room for combining economic liberalization policies with a more active social policy, as indeed the traditional international patterns seem to reflect. This calls for the reorientation of public expenditure towards the social sector and its targeting so as to maximize its favourable distributive effects. Some countries are also in a position to make an additional increase in social expenditure, thanks to higher tax income. Indeed, this is what the Chilean government did in the early 1990 s, without thereby adversely affecting real investment or economic growth. In such a case, the net distributive impact will depend on the manner of financing.

\section{III}

\section{Social policy and second-generation reforms}

The efforts to increase and target social expenditure in the region must be complemented with a substantial reorganization of the sector in order to make the supply of social services more efficient and efficacious. This is one of the central issues in the so-called second-generation reforms, the basic purpose of which is to improve the efficiency of the markets and introduce microeconomic rationality criteria in the supply of those services where this has previously been lacking.

The debates on social services have been aimed at bringing competition into their supply (creation of quasi-markets), introducing the participation of private agents, and making changes in the forms of State support (changing from the traditional supply subsidies to demand subsidies). At the same time, and in a complementary manner, the supply of those services still provided by the State has been decentralized, new systems of public management designed to get results have been created, effective autonomy has been given to the public bodies responsible for providing services, and citizen participation mechanisms have been established for the control of public management. All the components in this reorganization -but especially the first-namedare designed to deal with the "government flaws" which became evident in the past in the supply of social services and are reflected in inefficiency and low quality of services provided by the State.
Experience shows that the private sector responds dynamically to the incentives given to it. It also shows, however, that the participation of that sector is likewise subject to "market flaws": both those of a traditional nature, relating to economies of scale, and those associated with problems of information, which give rise to phenomena of imperfect competition, adverse selection and moral risk (Ocampo, 1996).

In economies where there are big disparities in distribution, the most serious problem is the natural tendency generated by the market for the private sector to orient its supply -in terms of quantity and especially of quality- towards the highest-income sectors. This problem is not necessarily solved through a system of demand subsidies, and the State should therefore design instruments to increase the supply directed towards the lower income sectors. As public supply, in many cases, has been equally incapable of reaching certain sectors of the population (as in the case of low-cost housing programmes, for example), it is necessary to promote new agents, generally of a cooperative or community nature.

The above difficulties become still more marked when systems of private participation do not include clear principles of solidarity, as the health system in Chile shows. In this case, adverse selection can become very marked, both as regards economic and social strata and the health risks associated with the age of the population covered. The introduction of 
solidarity elements does not automatically solve the problem, however. Thus, for example, in order to avoid these difficulties the health system reform in Colombia provided that benefits must be completely independent of the amount of contributions, but even so the private sector response for the poorest strata was very frustrating in the initial phase.

The private sector response can also be geographically unbalanced: it may be quite good in the larger cities but insufficient in small towns or the rural sector, where -because of the very low economies of scale- there may be "natural monopolies" in many services when their supply is not profitable.

When the response of supply to the incentives generated by demand subsidies is inadequate in terms of quantity or quality, it may be desirable to design intermediate systems, termed perhaps "demandoriented supply subsidies", which can influence the supply and even the quality of the services provided and at the same time afford the traditional benefits of demand subsidies in terms of the targeting of beneficiaries. These systems consist of the establishment of contracts with selected agents for the supply of services to a specific group of the population, through a system of competitions or through the promotion of community or cooperative organizations for the explicit purpose of entrusting them with the administration of the corresponding services. This can also be a suitable scheme for promoting the creation of new services or improving the quality of existing ones (for example, for raising the quality of the educational system, as is being done in Chile).

Problems of information are much more serious in the services markets than in those for goods. In particular, there are extremely serious imbalances between the information available to the suppliers of highly specialized services and that available to the recipients of the services. This is especially so in the case of the doctor-patient relationship in the health sector, but similar phenomena are also observed in education. For this reason, the development of quasimarkets for the supply of social services requires the establishment of schemes to ensure at least a minimum of information and highly developed instruments for the protection of users.

Private sector participation and the creation of quasi-markets open up good opportunities for doing away with some long-standing problems associated with the public supply of social services, but they are not a panacea. The above-mentioned problems and those connected with the development of the necessary institutions for overcoming them must not be underestimated. The reforms adopted in this framework must therefore be pragmatic and must include a substantial component of graduality and learning from experience. Moreover, it must be borne in mind that the new systems of private sector participation are not a substitute for the public supply of services in all sectors. For this reason, it may be desirable to design mixed systems in which public and private agents operate in competition with each other. In many cases, however, competition is not feasible. For this reason, efforts to improve public supply through decentralization, result-oriented public management, autonomy of the bodies responsible for supplying services, and citizen control are essential and basic elements of any reform in the area of social services.

Finally, it should be emphasized that one of the main objectives of reforms to the social services should be the design of suitable systems of regulation, information and quality control in respect of the services provided. This is particularly important when, because of the specialized nature of the services, there is no guarantee of the full and transparent information that consumers need in order to choose their suppliers. This is a matter which is still at an incipient stage and to which considerable efforts should be devoted in the years to come.

Consequently, microeconomic efficiency should be an important guideline in the second- generation reforms, but so too should be equity. In the area of social policy, these reforms should be pragmatic and multi-faceted. They should take advantage not only of the opportunities provided by greater participation of private bodies in the supply of social services, but also of the potential benefits offered by wellmanaged public bodies subject to competition, when that is feasible. Furthermore, they should be aimed at correcting the shortcomings observed in both systems, including in particular the difficulty in ensuring that the poorest sectors of the population are provided with services and the lack of suitable systems of information and quality control in respect of the services provided.

(Original: Spanish) 


\section{Bibliography}

Berry, A. (1997): Chapter 1: The income distribution threat in Latin America, in A. Berry (ed.), Economic Reforms, Poverty, and Income Distribution in Latin America (in the press).

Birdsall, N. and J. L. Londoño (1997): Asset Inequality Does Matter: Lessons from Latin America, Working Paper No. 344, Washington, D. C., Inter-American Development Bank (IDB).

ECLAC (Economic Commission for Latin America and the Caribbean) (1990): Una estimación de la magnitud de la pobreza en Chile, 1987, LC/L.599, Santiago, Chile.

(1997): The Equity Gap. Latin America, the Caribbean and the Social Summit, LC/G.1954/Rev.1-P, Santiago, Chile. United Nations publication, Sales No. E.97.II.G.11.

(1998): The Fiscal Covenant. Strengths, Weaknesses, Challenges, LC/G.2024, Santiago, Chile, April.

IDB (Inter-American Development Bank) (1997): Economic and Social Progress in Latin America. Report 1997, Washington, D. C.
ILO (International Labour Organisation) (1997): Panorama laboral '97, Geneva.

Morley, S. A. (1994): Poverty and Inequality in Latin America: Past Evidence, Future Prospects, Policy Essay No. 13, Washington D. C., Overseas Development Council (ODC).

Ocampo, J. A. (1996): Participación privada en la provisión de servicios sociales: el caso colombiano, Coyuntura social, No. 14, Santafé de Bogotá, Tercer Mundo Editores, May.

Robbins, D. (1996): Evidence on Trade and Wages in the Developing World, Technical Paper No. 119, Paris, Organization for Economic Cooperation and Development (OECD), OECD Development Centre.

Rodrik, D. (1997): Has Globalization Gone Too Far?, Washington, D. C., Institute for International Economics (IIE).

UNCTAD (United Nations Conference on Trade and Development) (1997): Trade and Development Report 1997, New York. 